\title{
Effect of Antenatal Betamethasone Administration on Neonatal Cardiac Autonomic Balance
}

\author{
LEONHARD SCHÄFFER, TILO BURKHARDT, MAREN TOMASKE, SINA SCHMIDT, FRANZISKA LUZI, MANFRED RAUH, \\ ANTONIO LEONE, AND ERNST BEINDER
}

\begin{abstract}
Departments of Obstetrics and Gynecology [L.S., T.B., S.S., F.L., E.B.], Pediatric Cardiology [M.T.], and Neonatology [A.L.],University Hospital of Zürich, Zürich 8091, Switzerland; Department of Pediatrics [M.R.], University Hospital of Erlangen,
\end{abstract} Erlangen 91054, Germany

\begin{abstract}
Beneficial effects of antenatal glucocorticoid treatment in pregnancies at risk for preterm delivery may entail long-term consequences for the establishment of sympathoadrenergic system balance. We analyzed the cardiac autonomic system activity in neonates with a single course of antenatal betamethasone $(2 \times 12$ $\mathrm{mg}$ ) treatment by calculating heart rate variability (HRV) timedomain parameters from $24 \mathrm{~h}$ ECG recordings and short-term frequency-domain parameters during infant active and resting states. In addition, resting and challenged salivary $\alpha$-amylase levels were measured in 23 betamethasone-exposed neonates and compared with controls. Indicators for overall HRV (SDNN: $p=0.258$; triangular index: $p=0.179$ ) and sympathovagal balance [low- to highfrequency power (LF/HF): $p=0.82$ (resting state)] were not significantly different in neonates of the betamethasone treatment group. Parameters mostly influenced by sympathetic activity [SD of the average of valid NN intervals (SDANN): $p=0.184$ and SDs of all NN intervals (SDNNi): $p=0.784$ ] and vagal tone [RMSSD: $p=1.0$; NN50: $p=0.852$; HF: $p=0.785$ (resting state)] were unaltered. Resting $\alpha$-amylase levels were not significantly different in the betamethasone treatment group ( $p=0.304)$; however, $\alpha$-amylase release after a neonatal challenge was slightly reduced $(p=0.045)$. Thus, cardiac autonomic balance seems to be preserved in neonates exposed to a single course of antenatal betamethasone treatment.

(Pediatr Res 68: 286-291, 2010)
\end{abstract}

$\mathrm{A}$ ntenatal glucocorticoid treatment for lung maturation in pregnancies at risk for preterm delivery is an established method to reduce neonatal mortality and morbidity (1). However, there is accumulating evidence that glucocorticoids may alter maturational development and homeostasis of fetal regulatory systems. Repeated antenatal glucocorticoid exposure results in reduced birth weight, increased blood pressure, and glucose levels in adult offspring in different animal models (2).

The cardiac autonomic system has been shown to be sensitive toward antenatal glucocorticoids. Accordingly, fetal heart rate (FHR) variation is altered at least transiently in human fetuses after antenatal glucocorticoids $(3,4)$, and infant heart rate answer to a stress event is significantly increased (5). Putative mechanisms include an altered cardioregulatory innervation and signaling that seem to happen at central levels and at the level of the cardiomyocyte according to rodent models $(6,7)$.
Cardiovascular system regulation strongly depends on sympathetic autonomic control that is believed to play an important role in the pathogenesis of cardiovascular disease in the adult $(8,9)$. Long-term observations in adolescents and young adults with antenatal exposure to glucocorticoids have rather focused on classic signs of disease manifestation such as blood pressure $(10,11)$. However, risk factors for cardiovascular or metabolic disease may transform into apparent clinical manifestation at a more advanced age when stability of these systems can be less compensated by the organism. Therefore, we focused on putative predictive methods characterizing sympathoadrenergic cardiac balance. Heart rate variability (HRV) is a well-established noninvasive measure of cardiac autonomic control $(12,13)$ that is regulated by a complex interplay of sympathetic and parasympathetic branches of the autonomic nervous system. The aim of this study was to analyze the cardiac autonomic balance of healthy newborns at or near term who had received a single course of antenatal betamethasone treatment for imminent preterm delivery before $34 \mathrm{wk}$ of gestation and in whom delivery was delayed for a median of more than $7 \mathrm{wk}$. Electrophysiological HRV data were supplemented by functional salivary $\alpha$-amylase measurements in response to a stress stimulus. Salivary $\alpha$-amylase has been suggested to be a surrogate for cardiovascular autonomic system balance correlating well with HRV parameters $(14,15)$.

\section{METHODS}

The study was approved by the Research Ethics Committee of the University of Zurich and conforms with the Declaration of Helsinki. Written parental consent was obtained from all participants. ${ }^{1}$

Healthy infants born after 34 wk of gestation ( $>238 \mathrm{~d}$ postmenstruation) were included in the study. Exclusion criteria were infant intensive care treatment or invasive procedures, malformations, maternal substance abuse (nicotine and alcohol) during pregnancy, or insufficient amounts of saliva collected. No signs of clinical apparent infections were present in both groups. Sonographic measurements of fetal crown-rump length and biparietal diameter during the first trimester served as parameters for accurate determination 
Table 1. Neonatal and maternal baseline characteristics for HRV measurements and salivary $\alpha$-amylase measurements

\begin{tabular}{|c|c|c|c|c|c|c|}
\hline & \multicolumn{3}{|c|}{ HRV measurements } & \multicolumn{3}{|c|}{$\alpha$-Amylase measurements } \\
\hline & $\begin{array}{l}\text { Control } \\
(n=23)\end{array}$ & $\begin{array}{l}\text { Treatment group } \\
\quad(n=23)\end{array}$ & $p$ & $\begin{array}{l}\text { Control } \\
(n=40)\end{array}$ & $\begin{array}{l}\text { Treatment group } \\
\quad(n=23)\end{array}$ & $p$ \\
\hline Gestational age (d) & $275(239-293)$ & $260(245-289)$ & 0.0504 & $273(240-294)$ & $266(242-284)$ & 0.201 \\
\hline Birth weight (g) & $3260(2150-3830)$ & $3040(2170-3750)$ & 0.2104 & $3288(2100-3780)$ & $2950(2220-3930)$ & 0.269 \\
\hline Weight percentile & $54.8(15.4-82.6)$ & $50.0(15.2-88.9)$ & 0.7334 & $52(17.6-91.6)$ & $39(11.9-87.3)$ & 0.617 \\
\hline Male/female & $3 / 20$ & $12 / 11$ & 0.011 & $18 / 22$ & $13 / 10$ & 0.907 \\
\hline Head circumference & $34(31-37.5)$ & $34.5(31-36.5)$ & 0.7402 & $34.5(32.5-36)$ & $34(32-37)$ & 0.583 \\
\hline 5-Min APGAR & $9(8-10)$ & $9(8-10)$ & 0.7571 & $9(8-10)$ & $9(8-9)$ & 0.517 \\
\hline Maternal age (y) & $30(16-41)$ & $30(21-41)$ & 0.8342 & $30(18-39)$ & $29(23-37)$ & 0.496 \\
\hline Parity & $1(1-3)$ & $1(1-4)$ & 0.6088 & $2(1-4)$ & $1(1-3)$ & 0.040 \\
\hline Maternal pregestational BMI & $21.1(18.9-31.2)$ & $19.7(17.7-36.9)$ & 0.1142 & $23(16-38.6)$ & $21.3(18.3-36.9)$ & 0.100 \\
\hline Maternal BMI at delivery & $26.0(22.2-32.8)$ & $24.9(21.8-39.6)$ & 0.5774 & $27.7(23.7-41.9)$ & $26.2(21.8-39)$ & 0.153 \\
\hline Gestational age at steroid administration (d) & & $219(178-238)$ & & & $204(173-235)$ & \\
\hline
\end{tabular}

Data are median (range) unless otherwise specified.

BMI, body mass index.

of gestational age. Because mothers did not always give consent for both ECG and saliva sample collection, the populations were analyzed separately.

HRV measurements. A cohort of 23 infants with antenatal betamethasone treatment was recruited for $24 \mathrm{~h}$ Holter ECG measurements (treatment group). The control group of 23 infants without antenatal betamethasone exposure is part of a cohort previously published (16). A summary of infant and maternal characteristics is shown in Table 1. Three-channel Holter monitors (Lifecard CF; Delmar Reynolds Medical, Hertford, United Kingdom) were placed within the third to fourth postnatal day. Ectopic beats, noisy data, and artifacts were manually identified and excluded from the HRV analysis. For calculation of HRV parameters, the HRV Analysis Software, version 9.3.0 from Nevrokard (www.nevrokard.eu) was applied.

To account for long-term and for short-term HRV variations, the total monitoring period of $24 \mathrm{~h}$ was analyzed for time-domain parameter calculation, and selected 5-min segments were analyzed for frequency-domain parameter calculation to account for different states of activation. According to the recommendations of the Task Force of the European Society of Cardiology and North American Society of Pacing and Electrophysiology (17) and the literature for neonatal HRV measurements (18-21), the following parameters were analyzed.

Time-domain parameters [calculated from the total monitoring period (24 h)]. 1) Parameters as estimate of overall HRV: the SD of all valid NN intervals (SDNN), 2) parameters mostly influenced by parasympathetic activity: The ratio of the number of all pairs of adjacent NN intervals differing by $>50 \mathrm{~ms}$ and the total number of RR intervals (\%) (s-NN50), $>27 \mathrm{~ms}$ (s-NN27) and $>20 \mathrm{~ms}$ (s-NN20), the average of the hourly square root of the mean of the sum of the squares of differences between adjacent $\mathrm{NN}$ intervals (RMSSD), 3) parameters mostly influenced by sympathetic activity: The SD of the average of valid NN intervals (SDANN) in 5-min segments in the recording, the average of the hourly means of SDs of all NN intervals (SDNNi) in 5-min segments. As geometric index, the HRV triangular index, defined by the total number of all NN intervals divided by the height of the histogram of all NN intervals measured on a discrete scale with bins of 7.8125 $\mathrm{ms}$ as estimate of overall HRV was calculated.

Frequency-domain parameters (5 min segments). Power spectral analysis was calculated by fast Fourier transformation (Hamming window) in three main spectral components. To account for the neonatal physiology, frequency bandwidths were adjusted according to the literature $(18,19)$ : high frequency $(\mathrm{HF})$ : 0.24 to $1.04 \mathrm{~Hz}$, representing parasympathetic activity; low frequency (LF): 0.04 to $0.24 \mathrm{~Hz}$, representing both, sympathetic and parasympathetic activity; and very low frequency (VLF): 0.003 to $0.04 \mathrm{~Hz}$ with a less-defined physiologic role. Total power $\left(\mathrm{ms}^{2}\right)$ and the ratio of LF/HF considered as a marker of sympathetic-parasympathetic system balance were analyzed. Absolute values $\left(\mathrm{ms}^{2}\right)$ and normalized units (n.u.) that represent the relative value of each power component in proportion to the total power minus the VLF component were calculated. The presentation of LF and HF in n.u. emphasized the controlled and balanced behavior of the two branches of the autonomic system (17).

$\boldsymbol{\alpha}$-amylase measurements. Salivary $\alpha$-amylase levels were analyzed from a cohort of 23 infants with antenatal betamethasone treatment and from a cohort of 40 controls that have been published previously (22). A summary of infant and maternal characteristics is shown in Table 1.

Samples were collected using a routinely performed blood sampling (heel prick test) 72 to $96 \mathrm{~h}$ postpartum as pain-induced stress factor. This procedure has been shown to be a significant stressor for the newborn $(23,24)$, and salivary $\alpha$-amylase has been suggested as a measure of endogenous adrenergic activity and changes in the autonomic nervous system in general $(15,25)$ and specifically for cardiac autonomic balance $(14,15,26)$. Saliva samples were collected from each infant $10 \mathrm{~min}$ before and 5 and $20 \mathrm{~min}$ after stress induction. Collection time was based on experiments revealing peak $\alpha$-amylase responses between 5 and 10 min poststress induction $(15,27)$. A cotton swab was placed in the neonates' mouth for a collection time of $5 \mathrm{~min}$. Samples were placed in saliva collection tubes (Salivette; Sarstedt, Nümbrecht, Germany) and stored frozen at $-20^{\circ} \mathrm{C}$ until further analysis.

The amylase 4,6-ethylidene- $p$-nitrophenyl- $\alpha$,D-maltoheptaoside (EPS) method from Roche Diagnostics, Mannheim, Germany, was applied for the measurement of the $\alpha$-amylase concentration in saliva. The diluted saliva samples $(1+9)$ were analyzed on the Integra system 800 . The assays showed good performance characteristics [intraassay coefficient of variation $(\mathrm{CVs})<$ $1.0 \%$ and interassay $\mathrm{CVs} \leq 1.3 \%$ at concentrations of 79.9 and $198 \mathrm{U} / \mathrm{L}]$.

Statistical analysis. All statistical analyses were performed with STATA 10 Statistics/Data Analysis Software (Stata Corporation, College Station, TX). Baseline characteristics of treatment and control infants were compared using the Mann-Whitney test and $\chi^{2}$ test when appropriate. Because HRV parameters were not normally distributed as analyzed by the Shapiro-Francia W' test, we compared groups using the Mann-Whitney test. $\alpha$-Amylase data were log transformed. The Mann-Whitney test was used for comparison of baseline $\alpha$-amylase levels. Alterations of log-transformed data between baseline and poststimulation levels were analyzed by the Wilcoxon signed-rank test. To account for within-subject variation, a two-way ANOVA for repeated measurements was conducted. A stepwise multiple regression was applied to analyze the impact of gestational age at steroid administration, birth weight percentile, and gestational age at delivery as putative influencing factors on $\alpha$-amylase values. The level of statistical significance of all analyses was set at $p<0.05$.

\section{RESULTS}

Infant HRV. Betamethasone treatment was conducted at a median gestational age of $219(178-238) \mathrm{d}$ (corresponding to $312 / 7$ wk of gestation), and the median interval between treatment and delivery was 51 (25 to 108$) \mathrm{d}$. Median birth weight and weight percentile were comparable between treatment and control groups (3040 $\mathrm{g}$ and 50th percentile versus $3260 \mathrm{~g}$ and 54.8 th percentile). Infants of the treatment group were delivered $\sim 2$ wk earlier [ $260 \mathrm{~d}(371 / 7$ wk of gestation) versus $275 \mathrm{~d}$ (39 2/7 wk of gestation], just not reaching statistical significance $(p=0.0504)$. Infant head circumference and 5-min Apgar levels were similar $(p=0.740$ and $p=0.757$, respectively). A summary of the characteristics of the study population is depicted in Table 1.

For the long-term HRV analysis, the time-domain parameters SDNN and the triangular index representing estimates for 
Table 2. Long-term time-domain HRV parameters in control and treated (betamethasone) group

\begin{tabular}{|c|c|c|c|c|c|c|c|}
\hline & \multicolumn{2}{|c|}{ Median } & \multicolumn{2}{|c|}{ Minimum } & \multicolumn{2}{|c|}{ Maximum } & \multirow[b]{2}{*}{$p$} \\
\hline & Control & Treated & Control & Treated & Control & Treated & \\
\hline HR (bpm) & 126 & 132 & 112 & 112 & 152 & 137 & 0.4218 \\
\hline Mean NN (ms) & 478.2 & 455.9 & 395.5 & 438.5 & 538.2 & 534.4 & 0.3976 \\
\hline Triangular index & 20 & 17 & 8 & 10 & 34 & 28 & 0.1792 \\
\hline s-NN50 (\%) & 2.46 & 2.13 & .14 & .26 & 11.56 & 12.76 & 0.8519 \\
\hline s-NN27 (\%) & 10.97 & 10.43 & 1.71 & 2.54 & 29.92 & 29.05 & 0.6844 \\
\hline s-NN20 (\%) & 20.6 & 18.6 & 4.61 & 7.09 & 42.4 & 38.5 & 0.8176 \\
\hline SDNN (ms) & 69.92 & 65.82 & 31.88 & 39.83 & 108.4 & 96.97 & 0.2579 \\
\hline SDNNI (ms) & 42.58 & 42.62 & 18.79 & 27.1 & 61.38 & 69.55 & 0.7836 \\
\hline r-MSSD (ms) & 19.4 & 18.04 & 10.54 & 11.74 & 36.27 & 41.31 & 1.0000 \\
\hline SDANN (ms) & 52.0 & 51.25 & 24.11 & 21.96 & 85.18 & 70.96 & 0.1838 \\
\hline
\end{tabular}

Table 3. Short-term frequency-domain HRV parameters in control and treated (betamethasone) group

\begin{tabular}{|c|c|c|c|c|c|c|}
\hline & \multicolumn{3}{|c|}{ Active state } & \multicolumn{3}{|c|}{ Resting state } \\
\hline & Control & Treated & $P$ & Control & Treated & $p$ \\
\hline $\mathrm{HF}\left(\mathrm{ms}^{2}\right)$ & $318.75(15.80-2251.78)$ & $252.12(12.77-911.21)$ & 0.3242 & $51.92(14.69-184.32)$ & $58.31(9.20-166.71)$ & 0.7853 \\
\hline HF (n.u.) & $0.48(0.20-0.99)$ & $0.42(0.19-2.26)$ & 0.3478 & $0.18(0.08-0.31)$ & $0.17(0.07-0.30)$ & 0.8204 \\
\hline $\mathrm{LF}\left(\mathrm{ms}^{2}\right)$ & $263.61(14.48-2246.17)$ & $402.24(42.73-1185.95)$ & 0.7424 & $263.61(14.48-2246.17)$ & $402.24(42.73-1185.95)$ & 0.8916 \\
\hline LF (n.u.) & $0.52(0.01-0.80)$ & $0.61(0.24-2.03)$ & 0.1522 & $0.82(0.69-0.92)$ & $0.83(0.70-0.93)$ & 0.8204 \\
\hline $\mathrm{VL}\left(\mathrm{ms}^{2}\right)$ & 79.96 (8.63-1482.97) & $147.68(8.87-170.47)$ & 0.3981 & $317.36(47.01-899.14)$ & $214.62(55.83-1030.80)$ & 0.0565 \\
\hline Total power $\left(\mathrm{ms}^{2}\right)$ & $857.90(38.91-3612.32)$ & $818.24(75.00-2967.94)$ & 0.4668 & $791.37(157.43-1495.71)$ & $618.09(150.45-1623.06)$ & 0.2288 \\
\hline $\mathrm{LF} / \mathrm{HF}$ & $1.06(0.32-4.30)$ & $1.38(0.32-4.30)$ & 0.2699 & $4.47(2.24-11.68)$ & $4.82(2.34-13.08)$ & 0.8204 \\
\hline
\end{tabular}

Values are given as medians (range).

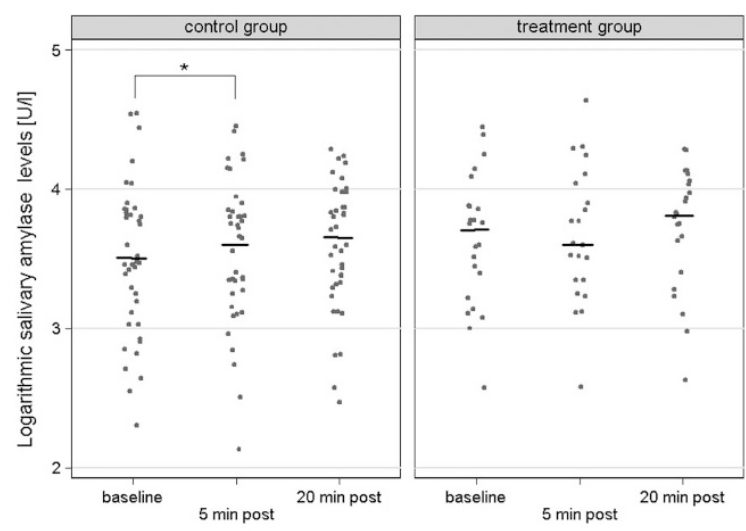

Figure 1. Individual log-transformed salivary levels and medians for $\alpha$-amylase in control $(n=40)$ and study group $(n=23)$ newborns before (baseline) and after (5 and $20 \mathrm{~min}$ after) application of the stress stimulus. (left = control; right $=$ study group). Horizontal line indicates median levels. ${ }^{*} p<0.05$.

overall HRV were not significantly different in the treatment group compared with the controls $(p=0.258$ and $p=0.179$, respectively). Similarly, parameters, mostly influenced by sympathetic activity, such as SDANN and SDNNi were similar $(p=0.184$ and $p=0.784)$. No significant differences were also found for estimates of vagal tone as $\operatorname{RMSSD}(p=$ $1.0)$ and for the proportion of pairs of adjacent $\mathrm{NN}$ intervals differing by $>50,>27$, and $>20 \mathrm{~ms}(p=0.852, p=0.684$, and $p=0.818$; Table 2). Short-term HRV analysis during active and resting states calculating frequency-domain parameters confirmed these results. Although there was a significant difference between active and resting states within each group as expected (data not shown), comparison of parameters between similar states of activation were not significantly dif- ferent when calculating absolute and normalized values. Accordingly, HF, representing vagal activity; LF, representing both sympathetic and vagal activity; VLF, representing total power; and $\mathrm{LF} / \mathrm{HF}$, representing sympathovagal balance, all were not significantly different from control infants (Table 3). The likelihood to miss a putative significant difference by our sample size is very low [5.2\% $(\alpha=0.8, \beta=0.05)$ for RMSSD and LF/HF (n.u.) resting state].

Infant $\alpha$-amylase levels. Betamethasone treatment was conducted at a median gestational age of 201 (173-235) d, and the median interval to delivery was $55(16-102)$ d. Median birth weight and weight percentile were comparable in both groups ( $p=0.269$ and $p=0.617$, respectively). Gestational age at delivery was $266(242-284) \mathrm{d}$ in the treatment group and $273(240-294) \mathrm{d}$ in the control group $(p=0.201)$. Head circumference and 5-min Apgar scores were similar $(p=$ 0.583 and $p=0.517$, respectively). A summary of the characteristics of the study population is shown in Table 1 .

Median baseline levels for $\alpha$-amylase were slightly higher but not significantly different in the treatment group when compared with controls $(p=0.3040$, Fig. 1$) . \alpha$-Amylase levels in control infants increased marginally, just reaching the level of statistical significance $(p=0.045)$ at the time point 5-min poststimulation, whereas in infants with betamethasone treatment, no significant alteration of $\alpha$-amylase release was observed $(p=0.408)$. A two-way ANOVA confirmed that there was a significant alteration of $\alpha$-amylase in the control ( $p=0.0266)$ but not in the study group $(p=0.183)$ after the stress stimulus. No significant influence of gestational age at steroid administration $(p=0.82)$, newborn weight $(p=$ $0.079)$, and gestational age at delivery $(p=0.46)$ was observed applying a multiple stepwise regression model. 


\section{DISCUSSION}

We have shown that cardiac autonomic system balance is preserved in the neonate after a single course of antenatal maternal betamethasone treatment for fetal lung maturation in pregnancies at risk for preterm delivery.

There is experimental evidence that intrauterine exposure to synthetic glucocorticoids affects balance and activity of the autonomic cardiovascular system. In adult male guinea pigs with repeated prenatal exposure to dexamethasone, arterial blood pressure was significantly elevated (28). Even a single course of glucocorticoid treatment produced a sustained elevation of blood pressure and altered baroreceptor heart rate response in fetal sheep and the baboon (29-32) and increased central and peripheral vascular resistance $(29,30,33)$. However, others only found transient hypertension after maternal dexamethasone treatment in fetal sheep (34). In the nonhuman primate, multiple antenatal dexamethasone exposure resulted in elevated systolic and diastolic blood pressure at the age of 12 mo (35).

The connection of prenatal glucocorticoid treatment and increased blood pressure in the human is less clear. In the neonate (36) and in a cohort of preterm children at the age of 14 y (37), blood pressure was significantly increased, whereas other data have shown that blood pressure alterations may rather be transient and normalize within the first few weeks of life (38). Large follow-up studies did not find significant alterations in blood pressure in nonstrained conditions at the age of 20 and $30 \mathrm{y}(10,11)$.

Data addressing more specifically the cardiac autonomic system reveal persistent abnormalities of cardiac noradrenergic innervation after intrauterine exposure to exogenous steroids in the rat (6) and alterations of cardiac intracellular $\beta$-adrenoceptor signaling (7). Furthermore, centrally located systems involved in cardioregulation such as the brainstem norepinephrine system seem to undergo premature maturation in response to prenatal synthetic glucocorticiod exposure (39). There is some evidence that betamethasone may even have a direct effect on the cardiac pacemaker $(40,41)$. It has been shown that infants with antenatal betamethasone treatment display a significant increase in heart rate in response to a stressor when compared with control infants (5).

To our knowledge, a systematic analysis of HRV parameters according to standardized methods (17) so far has not been performed in individuals exposed to prenatal glucocorticoid treatment. HRV is a well-established noninvasive measure of cardiac autonomic control that has been shown to be related to hypertension $(12,13)$ and to predict future adverse cardiovascular events in adults (42). HRV analyses have been suggested for putative prognostic use in children (43). We did not find significant alterations of any HRV parameter analyzed in neonates after antenatal betamethasone treatment. Studies measuring intrauterine FHR variation after steroid administration have produced inconsistent results. Mulder et al. (3), analyzing FHR short-term and long-term variation, found reductions in FHR variation after maternal betamethasone administration. In contrast, treatment with dexamethasone resulted in a significant rise in short-term FHR variation (4). However, both effects were only transiently observed.

We conducted our study in the neonatal period because our aim was to find out whether putative intrauterine steroid effects ultimately transform into permanent postnatal alterations of the cardiac autonomic system and to exclude postnatal-induced influencing factors of system adaptation. This aspect is even more important in consideration that diseases susceptible to intrauterine origin such as hypertension and type 2 diabetes will exhibit multiple system alterations at the time when they become apparent. For the development of prevention programs for arterial hypertension and type 2 diabetes, the initiating systems have to be identified and discriminated from systems secondarily affected. In this study, putative short-term effects could be excluded as the median interval between betamethasone treatment and delivery was more than $7 \mathrm{wk}$. Our findings provide new evidence that at the level of the cardiac autonomic subunit, at least, a single course of betamethasone does not primarily affect sympathetic cardiac balance.

As early effects may only become apparent during events with increased demand for adaptive regulation, we supplemented our electrophysiological studies with a neuroendocrinological approach by analyzing salivary $\alpha$-amylase levels during resting conditions and after a stressful stimulus. Salivary $\alpha$-amylase is secreted by acinar cells in the salivary glands that are richly innervated by both sympathetic and parasympathetic nerve fibers, influencing the release of $\alpha$-amylase by classic neurotransmitters (44). Studies in humans and animals have suggested that the activation of the autonomic nervous system leads to a high activity of salivary $\alpha$-amylase $(25,45-47)$. Furthermore, $\alpha$-amylase levels have been found to be associated with cardiovascular physiology and are suggested to be a surrogate for cardiovascular autonomic system balance (26). Bosch et al. (14) found a significant negative correlation between the parasympatheticinfluenced HRV parameter RMSSD and $\alpha$-amylase levels during stress induction in adults. Furthermore, a positive correlation between $\alpha$-amylase levels and LF/HF as surrogate for sympathetic tone has been shown (15), thereby making this parameter a promising indicator for cardiac autonomic function. Although studies on cardiovascular autonomic physiology using $\alpha$-amylase measurements have not been validated in neonates, several analyses from children support the strong relationship between salivary $\alpha$-amylase and sympathetic/ parasympathetic nervous system activation in younger individuals (26). Interestingly, we found stimulated $\alpha$-amylase levels in betamethasone-exposed neonates rather decreased when compared with controls although statistical significance was only marginal ( $p=0.045)$. One rather had expected increases in $\alpha$-amylase levels as response to an increased sympathetic stress reaction if betamethasone treatment had affected the system.

The slightly attenuated $\alpha$-amylase response might be explained by previous findings about the stress-regulating hypothalamo-pituitary-adrenal (HPA) axis. Indeed, we and others have shown that a single course of antenatal betamethasone administration causes sustained suppressive effects of HPA 
reactivity in these infants $(5,22,48)$. We speculate a nonsignificant increase in $\alpha$-amylase levels may be the result of inadequate HPA system sensitivity rather than direct effects of steroid exposure on the sympathetic system because these systems are closely interconnected. A stepwise multiple regression was conducted to exclude putative influencing factors such as gestational age at steroid administration, newborn weight, and gestational age at delivery, not revealing a significant influence on $\alpha$-amylase results.

We analyzed a relatively homogenous collective excluding isolated effects of severe prematurity, pregnancy complications such as intrauterine growth restriction or preeclampsia in addition to maternal substance abuse and diseases. Nevertheless, although not statistically significant, there was a difference of $15 \mathrm{~d}$ in gestational age between the control and the treatment group. This may, even though near or at term, entail a difference in perinatal maturation with a putative influence on the cardiac autonomic system. It has been shown that with increasing maturation of the sympathetic nervous system during the course of pregnancy, there is a shift of the sympathetic/ parasympathetic balance toward parasympathetic tone (4951). The time-domain parameter RMSSD has been shown to demonstrate highest correlation to gestational age (51), and for frequency-domain parameters, gestational age-dependent alterations of LF and HF parameters have only been found to be significant during resting and not during active states (49). Therefore, we analyzed our data for a putative influence of gestational age on these parameters and conducted a regression analysis. We found adjusted R-squared values for RMSSD of 0.10 , for LF/HF (resting state) of 0.00 , and for $\mathrm{LF} / \mathrm{HF}$ (active) of 0.02 , indicating no relevant effect of the difference in gestational age in our groups. Thus, our data strongly support the notion that at least the cardiac autonomic subunit of the sympathetic system is not permanently affected in utero by antenatal steroid treatment for lung maturation.

It is important to note that the sympathetic nervous system is composed of multiple function-specific subunits (52) and the programming of sympathetic nervous system function is believed to occur regionally rather than on a global basis, suggesting that subdivisions of the sympathetic nervous system may be influenced by different sets of environmental variables (53), thus aspects such as vascular bed regulation may be affected differently.

We cannot exclude that our methods were not sensitive enough to expose small alterations in cardiac sympathetic system balance that may only become apparent with increasing system maturation during infant and adolescent development. Even though long-term analyses of antenatal steroid treatment in young adults did not find sympathoadrenergic connected pathologies (10), these diseases may not be present until later ages at the time they usually become apparent. In fact, putative early markers of sympathetic cardiac activation such as HRV parameters have not been applied in these studies.

In conclusion, despite evidence from animal models, it seems that the neonatal cardiac autonomic system is primarily unaffected by a single course of betamethasone treatment for lung maturation. However, the impact of multiple doses is not known.

Acknowledgments. We thank Romaine Arlettaz-Mieth and Roland Zimmermann for support.

\section{REFERENCES}

1. Roberts D, Dalziel S 2006 Antenatal corticosteroids for accelerating fetal lung maturation for women at risk of preterm birth. Cochrane Database Syst Rev 3:CD004454

2. Seckl JR, Holmes MC 2007 Mechanisms of disease: glucocorticoids, their placental metabolism and fetal 'programming' of adult pathophysiology. Nat Clin Pract Endocrinol Metab 3:479-488

3. Mulder EJ, Koenen SV, Blom I, Visser GH 2004 The effects of antenatal betamethasone administration on fetal heart rate and behaviour depend on gestational age. Early Hum Dev 76:65-77

4. Dawes GS, Serra-Serra V, Moulden M, Redman CW 1994 Dexamethasone and fetal heart rate variation. Br J Obstet Gynaecol 101:675-679

5. Davis EP, Townsend EL, Gunnar MR, Georgieff MK, Guiang SF, Ciffuentes RF, Lussky RC 2004 Effects of prenatal betamethasone exposure on regulation of stress physiology in healthy premature infants. Psychoneuroendocrinology 29:1028-1036

6. Bian X, Seidler FJ, Slotkin TA 1993 Fetal dexamethasone exposure interferes with establishment of cardiac noradrenergic innervation and sympathetic activity. Teratology 47:109-117

7. Bian X, Seidler FJ, Olsen C, Raymond JR, Slotkin TA 1993 Effects of fetal dexamethasone exposure on postnatal control of cardiac adenylate cyclase: betaadrenergic receptor coupling to Gs regulatory protein. Teratology 48:169-177

8. Clark AL, Cleland JG 2000 The control of adrenergic function in heart failure: therapeutic intervention. Heart Fail Rev 5:101-114

9. de Champlain J, Gonzalez M, Lebeau R, Eid H, Petrovitch M, Nadeau RA 1989 The sympatho-adrenal tone and reactivity in human hypertension. Clin Exp Hypertens A 11:159-171

10. Dalziel SR, Walker NK, Parag V, Mantell C, Rea HH, Rodgers A, Harding JE 2005 Cardiovascular risk factors after antenatal exposure to betamethasone: 30-year follow-up of a randomised controlled trial. Lancet 365:1856-1862

11. Dessens AB, Haas HS, Koppe JG 2000 Twenty-year follow-up of antenatal corticosteroid treatment. Pediatrics 105:E77

12. Guzzetti S, Dassi S, Pecis M, Casati R, Masu AM, Longoni P, Tinelli M, Cerutti S, Pagani M, Malliani A 1991 Altered pattern of circadian neural control of heart period in mild hypertension. J Hypertens 9:831-838

13. Langewitz W, Ruddel H, Schachinger H 1994 Reduced parasympathetic cardiac control in patients with hypertension at rest and under mental stress. Am Heart J 127:122-128

14. Bosch JA, de Geus EJ, Veerman EC, Hoogstraten J, Nieuw Amerongen AV 2003 Innate secretory immunity in response to laboratory stressors that evoke distinct patterns of cardiac autonomic activity. Psychosom Med 65:245-258

15. Nater UM, La Marca R, Florin L, Moses A, Langhans W, Koller MM, Ehlert U 2006 Stress-induced changes in human salivary alpha-amylase activity-associations with adrenergic activity. Psychoneuroendocrinology 31:49-58

16. Schäffer L, Burkhardt T, Müller-Vizentini D, Rauh M, Tomaske M, Mieth RA, Bauersfeld U, Beinder E 2008 Cardiac autonomic balance in small-for-gestationalage neonates. Am J Physiol Heart Circ Physiol 294:H884-H890

17. Malik M; the Task Force 1996 Heart rate variability: standards of measurement, physiological interpretation and clinical use. Task Force of the European Society of Cardiology and the North American Society of Pacing and Electrophysiology. Circulation 93:1043-1065

18. Fortrat JO 2002 Inaccurate normal values of heart rate variability spectral analysis in newborn infants. Am J Cardiol 90:346

19. Rosenstock EG, Cassuto Y, Zmora E 1999 Heart rate variability in the neonate and infant: analytical methods, physiological and clinical observations. Acta Paediatr $88: 477-482$

20. Andriessen P, Oetomo SB, Peters C, Vermeulen B, Wijn PF, Blanco CE 2005 Baroreceptor reflex sensitivity in human neonates: the effect of postmenstrual age. J Physiol 568:333-341

21. van Ravenswaaij-Arts CM, Hopman JC, Kollee LA, Stoelinga GB 1990 The influence of physiological parameters on long term heart rate variability in healthy preterm infants. J Perinat Med 18:131-138

22. Schäffer L, Luzi F, Burkhardt T, Rauh M, Beinder E 2009 Antenatal betamethasone administration alters stress physiology in healthy neonates. Obstet Gynecol 113:1082-1088

23. Mantagos S, Koulouris A, Vagenakis A 1991 A simple stress test for the evaluation of hypothalamic-pituitary-adrenal axis during the first 6 months of life. J Clin Endocrinol Metab 72:214-216

24. Lewis M, Ramsay DS 1995 Developmental change in infants' responses to stress. Child Dev 66:657-670

25. Chatterton RT Jr, Vogelsong KM, Lu YC, Ellman AB, Hudgens GA 1996 Salivary alpha-amylase as a measure of endogenous adrenergic activity. Clin Physiol 16:433448

26. Granger DA, Kivlighan KT, el-Sheikh M, Gordis EB, Stroud LR 2007 Salivary alpha-amylase in biobehavioral research: recent developments and applications. Ann N Y Acad Sci 1098:122-144 
27. Nater UM, Rohleder N, Gaab J, Berger S, Jud A, Kirschbaum C, Ehlert U 2005 Human salivary alpha-amylase reactivity in a psychosocial stress paradigm. Int J Psychophysiol 55:333-342

28. Banjanin S, Kapoor A, Matthews SG 2004 Prenatal glucocorticoid exposure alters hypothalamic-pituitary-adrenal function and blood pressure in mature male guinea pigs. J Physiol 558:305-318

29. Derks JB, Giussani DA, Jenkins SL, Wentworth RA, Visser GH, Padbury JF, Nathanielsz PW 1997 A comparative study of cardiovascular, endocrine and behavioural effects of betamethasone and dexamethasone administration to fetal sheep. J Physiol 499:217-226

30. Fletcher AJ, McGarrigle HH, Edwards CM, Fowden AL, Giussani DA 2002 Effect of low dose dexamethasone treatment on basal cardiovascular and endocrine function in fetal sheep during late gestation. J Physiol 545:649-660

31. Koenen SV, Mecenas CA, Smith GS, Jenkins S, Nathanielsz PW 2002 Effects of maternal betamethasone administration on fetal and maternal blood pressure and heart rate in the baboon at 0.7 of gestation. Am J Obstet Gynecol 186:812-817

32. Dodic M, Moritz K, Wintour EM 2003 Prenatal exposure to glucocorticoids and adult disease. Arch Physiol Biochem 111:61-69

33. Schwab M, Roedel M, Anwar MA, Muller T, Schubert H, Buchwalder LF, Walter B, Nathalielsz W 2000 Effects of betamethasone administration to the fetal sheep in late gestation on fetal cerebral blood flow. J Physiol 528:619-632

34. Quaedackers JS, Roelfsema V, Fraser M, Gunn AJ, Bennet L 2005 Cardiovascular and endocrine effects of a single course of maternal dexamethasone treatment in preterm fetal sheep. BJOG 112:182-191

35. de Vries A, Holmes MC, Heijnis A, Seier JV, Heerden J, Louw J, Wolfe-Coote S, Meaney MJ, Levitt NS, Seckl JR 2007 Prenatal dexamethasone exposure induces changes in nonhuman primate offspring cardiometabolic and hypothalamic-pituitaryadrenal axis function. J Clin Invest 117:1058-1067

36. Kari MA, Hallman M, Eronen M, Teramo K, Virtanen M, Koivisto M, Ikonen RS 1994 Prenatal dexamethasone treatment in conjunction with rescue therapy of human surfactant: a randomized placebo-controlled multicenter study. Pediatrics 93:730736

37. Doyle LW, Ford GW, Davis NM, Callanan C 2000 Antenatal corticosteroid therapy and blood pressure at 14 years of age in preterm children. Clin Sci (Lond) 98:137-142

38. Mildenhall LF, Battin MR, Morton SM, Bevan C, Kuschel CA, Harding JE 2006 Exposure to repeat doses of antenatal glucocorticoids is associated with altered cardiovascular status after birth. Arch Dis Child Fetal Neonatal Ed 91:F56-F60

39. Slotkin TA, Lappi SE, McCook EC, Tayyeb MI, Eylers JP, Seidler FJ 1992 Glucocorticoids and the development of neuronal function: effects of prenatal dexamethasone exposure on central noradrenergic activity. Biol Neonate 61:326336

40. Dampney RA 1994 Functional organization of central pathways regulating the cardiovascular system. Physiol Rev 74:323-364

41. Bennet L, Kozuma S, McGarrigle HH, Hanson MA 1999 Temporal changes in feta cardiovascular, behavioural, metabolic and endocrine responses to maternally administered dexamethasone in the late gestation fetal sheep. Br J Obstet Gynaecol 106:331-339

42. Algra A, Tijssen JG, Roelandt JR, Pool J, Lubsen J 1993 Heart rate variability from 24-hour electrocardiography and the 2-year risk for sudden death. Circulation 88:180-185

43. Stewart JM 2000 Does heart rate variability explain increased blood pressure in adolescents? J Pediatr 137:6-8

44. Turner RJ, Sugiya H 2002 Understanding salivary fluid and protein secretion. Ora Dis $8: 3-11$

45. Asking B, Gjorstrup P 1987 Synthesis and secretion of amylase in the rat parotic gland following autonomic nerve stimulation in vivo. Acta Physiol Scand 130:439445

46. Schneyer CA, Hall HD 1991 Effects of varying frequency of sympathetic stimulation on chloride and amylase levels of saliva elicited from rat parotid gland with electrical stimulation of both autonomic nerves. Proc Soc Exp Biol Med 196:333-337

47. Steerenberg PA, van Asperen IA, van Nieuw Amerongen A, Biewenga A, Mol D, Medema GJ 1997 Salivary levels of immunoglobulin A in triathletes. Eur J Oral Sci 105:305-309

48. Davis EP, Townsend EL, Gunnar MR, Guiang SF, Lussky RC, Cifuentes RF, Georgieff MK 2006 Antenatal betamethasone treatment has a persisting influence on infant HPA axis regulation. J Perinatol 26:147-153

49. van Laar JO, Peters CH, Vullings R, Houterman S, Oei SG 2009 Power spectrum analysis of fetal heart rate variability at near term and post term gestation during active sleep and quiet sleep. Early Hum Dev 85:795-798

50. Schneider U, Frank B, Fiedler A, Kaehler C, Hoyer D, Liehr M, Haueisen J, Schleussner E 2008 Human fetal heart rate variability-characteristics of autonomic regulation in the third trimester of gestation. J Perinat Med 36:433-441

51. Van Leeuwen P, Lange S, Bettermann H, Gronemeyer D, Hatzmann W 1999 Fetal heart rate variability and complexity in the course of pregnancy. Early Hum Dev 54:259-269

52. Jänig W, McLachlan EM 1992 Characteristics of function-specific pathways in the sympathetic nervous system. Trends Neurosci 15:475-481

53. Young JB 2002 Programming of sympathoadrenal function. Trends Endocrino Metab 13:381-385 